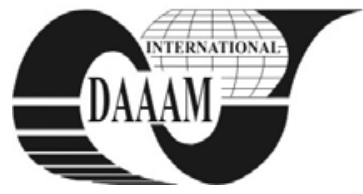

Annals of DAAAM for 2011 \& Proceedings of the 22nd International DAAAM Symposium, Volume 22, No. 1, ISSN 1726-9679 ISBN 978-3-901509-83-4, Editor B. Katalinic, Published by DAAAM International, Vienna, Austria, EU, 2011 Make Harmony between Technology and Nature, and Your Mind will Fly Free as a Bird Annals \& Proceedings of DAAAM International 2011

\title{
DAMAGE MECHANISM ANALYSIS OF DEVICE FOR THE WAVE SOLDERING
}

\author{
PROVAZNIK, M[artin]; KOLENAK, R[oman] \& MARTINKOVIC, M[aros]
}

\begin{abstract}
The paper deals with analysis of the degradation of soldering equipment integrated to the manufacturing of electronic components. The device is designed for wave soldering. Actually a lead-free SACX0307 solder is used. The analysis of damaged parts has revealed the presence of $\mathrm{Pb}$ from the previous lead-solder. The soldering equipment is the most damaged with dissolution of Fe in Sn matrix of lead-free solder. Key words: wave soldering, degradation, lead-free solder
\end{abstract}

\section{INTRODUCTION}

The lead solders were for a long time employed in industry owing to their optimum soldering properties and a low price. However, at present there is a strong effort to replace them by the lead-free variants. Often preferred alternative seem to be SAC (Sn-Ag-Cu) solders (Bath, 2007). Unfortunately, several problems have occurred at ther introduction into production. This is first of all the damage of soldering equipment, high maintenance costs and higher price of solders. Higher price of input components resulted in design of solders with lower Ag content, designated as SACX (Ganesan, 2006). The effect of lead-free solders on soldering equipment considerably differs from the effect exerted by lead solders. However, these new solders are often incorporated into production process on the same equipment and with the same technological procedures (Biocca, 2005). This article deals with analysis of damage caused to soldering equipment by SACX0307 solder (Gyemant, 2004; Morris, 2010).

\section{EXPERIMENTAL}

Fig. 1 indicate the equipment for wave soldering type Pillarhouse. This equipment was designed by customer's requirements for soldering the terminals of SMD crystals. The wave is formed by an immersion pump located in the soldering bathtub. Bathtub is heated from the bottom by resistance heating elements with a settable range of bath temperature up to $600{ }^{\circ} \mathrm{C}$. Loss of material on the functional parts of this equipment was observed since first application of new solders. The first indications of wear have occurred after 2 to 3 months of service on the parts of pump for liquid solder.

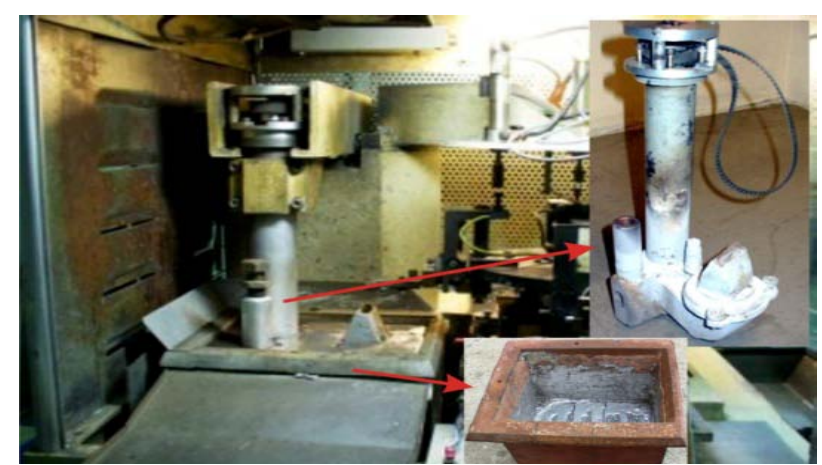

Fig. 1. Equipment for wave formation
The equipment for wave formation consists of the following parts (Fig. 2):

- nozzle - gray cast iron (Fig. 2-a),

- regulation screw - steel, wave height setting (Fig. 2-b),

- worm - gray cast iron, shaft - steel, sucks the solder from the bathtub and forces it through the nozzle (Fig. 2-c),

- equipment block - gray cast iron (Fig. 2-d).

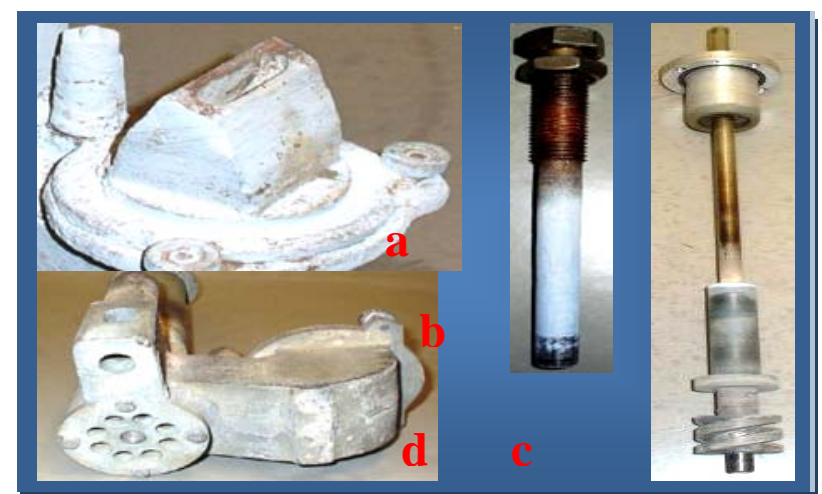

Fig. 2. Parts of equipment for wave formation

Bathtub of soldering equiment (Fig. 3), indicate visible traces of damage after half year of service. After 2 to 3 years the bathtub was perforated and the solder has run out through the hole. In order to prevent the leakage, the soldering bath was preliminary replaced. Analysis of degradation effect exerted on equipment by solder was realised in order to eliminate the need for overall replacement of the damaged parts of equipment.

Samples were taken from the following parts of soldering equipment:

- sample No. 1 - wall of the soldering bathtub,

- sample No. 2 - bottom of the soldering bathtub,

- sample No. 3 - immersed part of regulation screw.
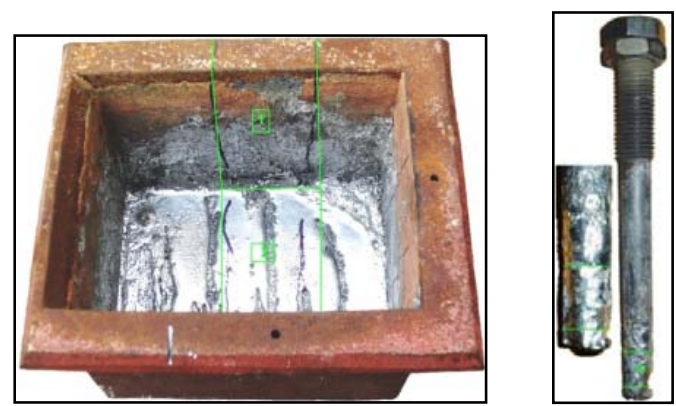

Fig. 3 Sampling from the soldering bathtub and setting screw

The lead-free solder type SACX0307 (99\% Sn, 0.3\% Ag, $0.7 \% \mathrm{Cu}$ ) is used for soldering. Material of soldering bathtub consists of gray cast iron with flake graphite. Material of regulation screw consists of stainless steel type AISI 304 (19.8\%Cr, 2.85\%Mn, 8.26\% Ni). 


\section{RESULTS}

For assessment of experimental part of work, the methods of light and electron scanning microscopy were applied. The effect of iron dissolution in tin matrix was studied by EDX analysis.

Microstructure of material boundary between soldering bathtub and solder deposit (sample No. 1) is indicate in Fig. 4. There are seen visible reaction products from dissolving the base metal in the solder. Dark grey demarcated grains in the solder matrix indicate an increased presence of iron and tin. Owing to presence of Fe content in solid solution of solder we can consider that erosion of the faying surface of cast iron is concerned. The extent of dissolution is affected not only by the soldering conditions but also by the amount of solder and its composition.

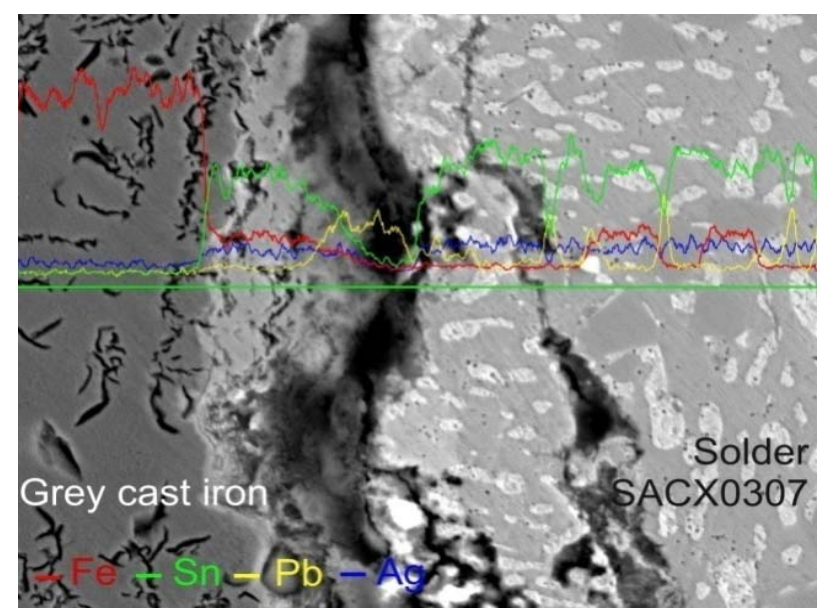

Fig. 4. SEM microstructure - sample No. 1 with quantitative analysis of content of elements

Microstructure of boundary of soldering tub bottom and solder deposit (sample No. 2) is indicate on Fig. 5. Dark grey demarcated grains on the joint boundary and also in solder matrix prove the dissolution of iron in tin and material loss in the soldering bathtub. Also ligh globular phases of lead are seen on the figure.

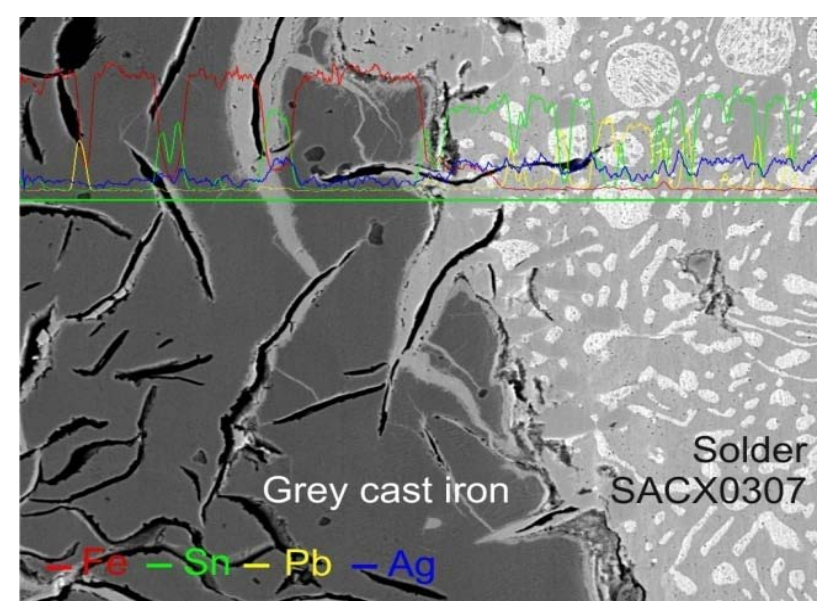

Fig. 5. SEM microstructure - sample No. 2 with quantitative analysis of content of elements

Fig. 6 indicate the microstructure of boundary between the regulation screw and solder (sample No. 3). An increased content of alloying elements $\mathrm{Cr}, \mathrm{Mn}$ and $\mathrm{Ni}$ from the stainless steel was observed in the solder matrix. We suppose that these compounds were released owing to erosion from the faying surface of steel screw by dissolution of iron in tin matrix of the lead-free solder. These components contaminate the charge in soldering tub and cause an increased reject rate.

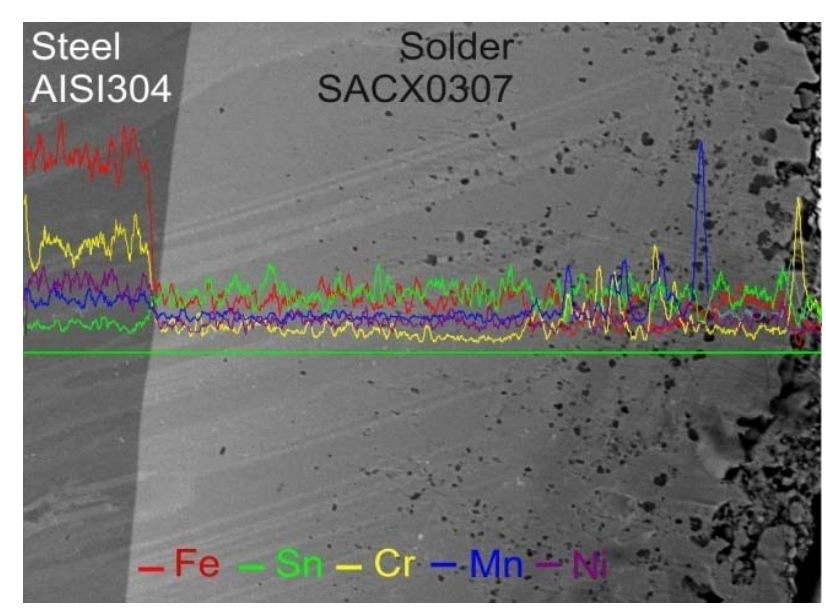

Fig. 6. SEM microstructure - sample No. 3 with quantitative analysis of content of elements

\section{CONCLUSION}

The results of experiments have undoubtedly proved the negative effect of SACX0307 solder on the non-treated parts of soldering equipment. Dissolution of iron in tin matrix is the main cause of wear. Presence of residual lead has resulted from the fact that in the analysed bathtub the lead solders $(\mathrm{Sn} 40 \mathrm{~Pb})$ and also lead-free (SAC) solders were simultaneously molten. In order to prevent further wear it was necessary to design the technology for protection of soldeting bathtub and pumping mechanism. Criterion of selection was based on reduced wear of functional parts. Several variants were tested, whereas the best results were achieved by spraying with heat-resistant paints and copper spray. Application of these agents resulted in considerable reduction of degradation effect of lead-free solder on the soldering equipment. This technology is financially less demanding than thermal spraying with ceramic $\mathrm{Al}_{2} \mathrm{O}_{3}$ coating. Regular treatment prevents the material loss and no peeling of protective coating was observed.

\section{ACKNOWLEDGEMENTS}

The contribution was prepared with the support of VEGA 1/0211/11 project - Development of lead-free solder for higher application temperatures and research of material solderability of metallic and ceramic materials.

\section{REFERENCES}

Bath, J. (2007). Led-free soldering, Springer, ISBN 9780387324661

Biocca, P. (2005). Lead-free Wave Soldering, Some Insight on How to Develop a Process that Works, Available from: http://www.specnor.com/pdf/Protecting_wave_solder_mac hines_from_the_corrosive_effects_of_Pb-free_solders.pdf Accessed: 2011-01-26

Ganesan, S. Pecht, M. (2006). Led-free electronics, Wileyinterscience, ISBN 978-0471786177

Gyemant, T. (2004). Protecting wave solder machines from the corrosive effects of $\mathrm{Pb}$-free solders, Available from: http://www.specnor.com/pdf/Protecting_wave_solder_mac hines_from_the_corrosive_effects_of_Pb-free_solders.pdf Accessed: 2011-01-26

Morris, J - O'Keefe, M. (2010). Equipment Impacts of LeadFree Wave Soldering, Available from: http://www.smtnet.com/library/files/upload/Soldering1.pdf Accessed: 2011-01-26 